\title{
Dados quantitativos na reflexão didática de estudantes e professores de História ${ }^{1}$
}

\author{
Quantitative data in the didactic reflection \\ of History students and teachers
}

Luis Fernando Cerri*

\section{Resumo}

Este ensaio discute as restrições verificadas no cotidiano acadêmico das áreas de Ciências Humanas no Brasil no que tange aos métodos quantitativos. Desenha-se um histórico da questão em seus aspectos epistemológicos, culturais e políticos e avalia-se a conjuntura atual em que as demandas científicas e sociais bem como os recursos tecnológicos recolocam o debate. Argumenta-se em favor das possibilidades analíticas dos métodos quantitativos para tratar desde outro ângulo questões que, no campo do ensino de História, vêm sendo trabalhadas quase exclusivamente por abordagens qualitativas, sobretudo estudos de caso. Procura-se demonstrar esses argumentos com a apresentação e discussão de alguns dados quantitativos no campo do ensino e aprendizagem histórica escolar e com o relato do uso desses dados em atividades de formação docente, terminando com a indicação de possibilidades futuras para o aprofundamento dessa relação.

Palavras-chave: Ciências Humanas; ensino de História; aprendizagem histórica; métodos quantitativos.

\section{Abstract}

This essay discusses the restrictions to quantitative methods verified at the academic life in the fields of Human Sciences at Brazil. A brief history of the subject is drawn, in its academic, cultural and political aspects, and it is argued that the present big picture of scientific and social demands, and also the new technological resources re-states this debate. It is argued in favour of the analytic possibilities to treat by another angle the issues that have been worked almost exclusively by qualitative approaches, mainly case studies. It is seek to demonstrate the arguments above with presentation and discussion of some qualitative data in the field of basic school History teaching and learning and with the narration of a use of those data in teachers training activity, ending with an appointment of future possibilities to deep this relationship.

Keywords: Human Sciences; History teaching; historical learning; quantitative methods.

\footnotetext{
* Doutor em Educação pela Universidade Estadual de Campinas (Unicamp). Docente do Departamento de História e dos mestrados acadêmico e profissional em História da Universidade Estadual de Ponta Grossa (UEPG). Ponta Grossa, PR, Brasil. lfcronos@yahoo.com.br
} 
Historiadores e pedagogos preocupados com o ensino de História que se aventurem a trabalhar com dados quantitativos devem estar dispostos para enfrentar questionamentos sobre a efetividade do método para as Ciências Humanas e para a educação. Os questionamentos vão desde objeções relativamente ingênuas até argumentos aprofundados que exigem respostas bastante elaboradas, mais com a pretensão de seguir o debate do que de fechar questão. Por exemplo: embora sejamos - nós, das humanidades - entusiastas de pesquisas qualitativas que trabalham com profundidade os depoimentos de um grupo restrito de pessoas ou mesmo de uma pessoa apenas, não raro estranhamos que uma pequena amostra de 120 jovens possa ser usada para falar de todos os jovens de uma cidade. Num raciocínio parecido, 4 mil participantes de uma amostra ainda parecem insuficientes para poder falar sobre todos os jovens de um continente. O que ocorre é que, no caso das entrevistas, a noção de representatividade não está em causa, mas na amostra quantitativa, diante do universo pesquisado, a representatividade da amostra parece sempre insuficiente. Diante da fragilidade de nosso conhecimento matemático e estatístico, somos tentados por um mapa, como no conto de Borges, tão preciso que cubra todo o reino mapeado. Por sua vez, o desenvolvimento mútuo de pensamento e linguagem na investigação e expressão dos avanços científicos, quando em busca de crescente precisão, demanda interdependência entre pensamento e matemática, entendida como linguagem que expressa um aspecto fundamental de grande parte dos objetos de pesquisa (Minayo; Sanches, 1993, p.240). Outro exemplo, ainda a título das dificuldades de nossa comunidade de ensino/pesquisa/pensamento, refere-se às formas da produção de dados, em si, dos métodos quantitativos. Um questionário fechado parece produzir um tipo de resposta totalmente conformado pela pergunta, ou seja, o respondente parece não dispor de liberdade suficiente para expressar um ponto de vista eventualmente não previsto pelo pesquisador ao planejar seu instrumento, ou ainda para escolher uma opção que esteja na posição intermediária entre duas dadas. Além disso, quando se trata de responder a questionários fechados em sala de aula, tendemos a imaginar que o estudante responde mais aquilo que o professor gostaria que ele respondesse do que aquilo que ele efetivamente pensa, ou seja, o questionário não parece nada seguro para evitar que o depoente minta em sua resposta, seja para ocultar uma opinião que é publicamente reprovada, seja para coincidir com a opinião dos colegas ou da professora. 
Entretanto, é possível afirmar, em direção aparentemente contrária, que as diferenças ou dicotomias entre métodos quantitativos e qualitativos na academia e na escola hoje encontram-se superadas. Dito isso, logo devemos engatar que se eu faço uma pesquisa quantitativa para descobrir se o professor é racista, provavelmente não se encontra o racismo, mas quando vou observar a aula ou recorro a outros meios não quantitativos, consigo perceber o racismo. Em suma, os resultados obtidos por métodos quantitativos não teriam muito a dizer para a prática de ensino dos professores. A resposta a um questionamento como esse tem duas partes: (1) se fizermos uma pesquisa quantitativa para descobrir se, para os docentes e pesquisadores, as dicotomias entre quantitativo e qualitativo estão superadas em sua prática, provavelmente a resposta será majoritariamente positiva, mas se formos fazer uma observação qualitativa sobre sua prática de pesquisa e de ensino, provavelmente vamos encontrar que essa separação e dicotomia continuam; (2) se alguém quer perguntar sobre racismo em uma pesquisa quantitativa para uma amostra que já tem diversos indícios de práticas racistas, e ainda assim não os encontra nos resultados, é porque provavelmente está fazendo isso de maneira errada.

Este texto se constrói em torno da perspectiva de demonstrar, de modo resumido, que as pesquisas de base quantitativa podem ter um impacto bastante positivo não só sobre as pesquisas que estudam o ensino e a aprendizagem, mas também sobre a prática de ensino dos professores. Para isso, defenderei que:

a) Boa parte das restrições que temos à pesquisa e à contribuição dos dados quantitativos derivam de nossa formação avessa aos números (há muitas anedotas internas à comunidade das Ciências Humanas e Sociais nesse sentido). As representações sobre os métodos quantitativos tendem a ser de maior descrença e em torno de sentimentos negativos em estudantes universitários de História e Antropologia, por exemplo, conforme estudo de Ramos e Carvalho (2009, p.29). Mais que isso, nossa formação epistemológica recente se dá no contexto de combate ao positivismo e ao neopositivismo e assemelhados, e tendemos a associar método e raízes epistemológicas de modo unívoco, o que é um exagero. Muitas dessas críticas qualitativistas aos métodos quantitativos são descritas por Chizzotti (2003).

b) As restrições que fazemos à pesquisa, aos dados e às conclusões geradas por métodos quantitativos quanto à sua efetividade - por exemplo, participantes não 
são absolutamente sinceros, as perguntas conformam as respostas, há possibilidade de que a interpretação do significado das perguntas e das respostas entre pesquisadores e respondentes seja dissonante -, tudo isso também afeta, de outros modos, os métodos qualitativos. Trata-se, para ambas as famílias de métodos, da mesma vigilância epistemológica e abertura à autocrítica e à crítica intersubjetiva.

c) Os dados e estudos quantitativos podem aportar contribuições fundamentais para a sala de aula de História que, de outro modo, não poderiam ser adquiridas pelo professor. Seja pelas dimensões da amostra, pelo tipo de pergunta, pela possibilidade de reduzir a grande quantidade de dados a poucos números ou a apenas um, seja pela possibilidade de controlar e deduzir a partir de variáveis.

\section{O quantitativo nas Ciências Humanas E SOCIAIS - REDEFINIÇÕES E LEgITIMIDADE}

O que nos oferecem as estatísticas? Uma massa de instrumentos que podem nos desviar do caminho se tentamos aplicá-las ao material sem reflexão suficiente, mas que, usadas com discernimento, podem ajudar a melhor compreender e explicar os fenômenos e as situações, contribuindo assim para a construção dos saberes. (Laville; Dione, 2007, p.204)

Que as Ciências Humanas tenham de se justificar ao usar métodos quantitativos não é uma situação generalizada no panorama internacional. Em alguns campos das Ciências Sociais, mesmo no Brasil, os estudos de estatística fazem parte da formação básica do graduando, e o uso de métodos estatísticos - aliados com a produção e a difusão cada vez mais ampla desse tipo de dado - cresce exponencialmente nas últimas décadas (Agresti; Finlay, 2012, p.17).

Por sua vez, a estatística já foi uma disciplina comum na grade da licenciatura em Pedagogia, por exemplo, mas hoje não se verifica mais esse espaço. Em História, um passado remoto testemunha a existência de uma história quantitativa e uma história serial (Barros, 2012) em décadas passadas: embora não totalmente desaparecidas, trata-se hoje de plantas exóticas no ecossistema acadêmico dos historiadores. Cabe construir algumas hipóteses sobre as mudanças nesse quadro até a situação que se verifica hoje, exercício que nos 
permite acompanhar a pergunta de Hartmut Günther: "pesquisa qualitativa versus pesquisa quantitativa: esta é a questão?” (Günther, 2006), assim como reconhecer, com Minayo e Sanches (1993), que a articulação e o trabalho conjunto de aspectos quantitativos e qualitativos da pesquisa são uma necessidade contemporânea.

Se precisamos hoje justificar o uso de métodos quantitativos nas Ciências Humanas - aqui, no ensino de História -, isso se deve a um processo anterior em que uma concepção neomoderna (no sentido de paradigma emergente pós-cartesiano) precisou bater-se contra a prevalência de um pensamento cientificista, neopositivista e/ou tecnicista. Pode-se recuperar, por exemplo, a luta dos estudos baseados em pesquisa participante ou da própria história oral para se afirmarem como ciência. Obviamente, esse confronto no campo da epistemologia terminou por colaborar com uma mudança de paradigma científico, e de mudança da própria concepção de ciência, de objeto, sujeito e verdade.

A crítica à racionalidade técnica e instrumental alinhou as iniciativas nas Ciências Humanas à necessidade de afirmação frente às outras ciências e de disputa de espaço e recursos. O timing desse enfrentamento foi diferente para as diferentes áreas, e a superação do modelo instrumental e técnico de razão e de ciência constituiu-se numa luta acadêmica e política, cognitiva e pedagógica. Exemplos de afirmação do novo modelo e superação do anterior podem ser identificados, por exemplo, na epistemologia freiriana, em que o processo educativo não é mais visto como o domínio de técnicas que permitiriam aos sujeitos (professores) moldar os objetos (os alunos) eficientemente à sua imagem. Pelo contrário, tratou-se de afirmar que professores e alunos interagem no processo educativo, ambos aprendem e ensinam, são e não são sujeitos e objetos de ensino e de aprendizagem. Assim, busca-se a superação da lógica formalista em que uma coisa é - apenas e tão somente - essa mesma coisa, e não outra. Essa provisoriedade e multiplicidade do ser tem o caráter político de recusar os processos de dominação de um pelo outro. De modo semelhante, a proposta metodológica da pesquisa-ação beneficia-se da possibilidade de o pesquisador ser também participante daquilo que pesquisa: pesquisador e pesquisado se mesclam, enfraquecendo a lógica da racionalidade técnica, que culmina nos meios para dominação do mundo e das pessoas por parte da ciência instrumentalizada pelo poder. Nesse imaginário revolucionário, os números (por exemplo, os números pelos quais o Banco Mundial impõe as 
ideias de fracasso educacional do terceiro mundo, culpabilização do professor, formação ideologizada de docentes) ficam emudecidos. É preciso, entretanto, argumentar em favor dessa criança, para que se lance fora apenas a água do banho: os números foram aí os mensageiros da ideologia, não a ideologia em si. O alvitre do cavalheirismo na arte da guerra recomenda que não se mate o mensageiro.

Critica-se também, nas pesquisas quantitativas no campo das Ciências Humanas, que esse método promove um ocultamento dos sujeitos nos processos. É forçoso reconhecer que, se é para ocultar a especificidade dos sujeitos, não é necessário o dado e o encaminhamento quantitativo (veja-se o pensamento althusseriano criticado por Thompson, 1981, por exemplo). Entretanto, pesquisas que focam nos sujeitos como os jovens - por exemplo, o projeto Youth and History (Angvik; Borries, 1997) - não só não elidem o papel do sujeito como podem-se descobrir relações que não eram sequer imaginadas ou eram apenas intuídas, e assim colaborar para a compreensão de identidades, papéis, expectativas etc. Por isso, coincidimos com o diagnóstico de Schmidt e Garcia, embora cumpra adicionar que as pesquisas que vão ao "chão da escola" também se beneficiam de pesquisas quantitativas, como foi o caso do projeto Youth and History e relacionados:

observa-se que, gradativamente, as pesquisas sobre o ensino, ao tomarem o caminho do "chão da escola", passaram a se sustentar efetivamente em dados mais qualitativos do que quantitativos, os quais introduzem novas preocupações e novos instrumentos metodológicos de investigação, como aqueles baseados na etnografia educacional. (Schmidt; Garcia, 2006, p.17)

Destaque-se ainda que por muito tempo nos foi imposta uma espécie de imperialismo científico dos métodos quantitativos, segundo o qual a única cientificidade possível para as Ciências Humanas era a quantificação. Impunha-se assim o padrão de objetividade das Ciências Exatas e Naturais como único confiável ou "científico", o que terminava por excluir outras técnicas e metodologias. Parte das consequências recaiu sobre um conformismo que passou a buscar autoafirmação em outros campos, confluindo para as perspectivas que afirmavam a História como arte, como saber específico e não científico, como ofício etc. Tal imposição e sua resistência duraram até que se disseminaram as incertezas no próprio campo das Ciências Exatas e Naturais, 
mas os vestígios dessa distinção primária permaneceram como ecos na cultura laboral dos cientistas das humanidades. No fundo, trata-se de uma disputa por recursos materiais, humanos e financeiros, bem como por prestígio social, o que nos leva a outra crítica, associada a essa: o alto custo da pesquisa quantitativa contribuiria para a elitização dos grandes projetos de pesquisa, colocando-os na dependência de fundações e corporações privadas. Essa avaliação já não é plenamente verdadeira, uma vez que as novas tecnologias de reconhecimento ótico de marcas em questionários eliminaram a necessidade de mão de obra de digitadores, assim como as práticas colaborativas permitem amostras com abrangência espacial e social relativamente grande. Além disso, a implantação de grandes exames nacionais - por exemplo, resultados do Exame Nacional do Ensino Médio (Enem) e Exame Nacional de Aprendizagem de Estudantes (Enade) - e a produção de bancos de dados para a avaliação institucional do ensino básico e superior geram amplas bases com variáveis riquíssimas, que permanecem subutilizadas em suas potencialidades para vários campos, mas notadamente para entender melhor os problemas do ensino de História.

No atual momento em que vigem outras bases epistemológicas de uma ciência em crise com os postulados modernos e em processo de construção de um novo paradigma, é necessário reconhecer que as críticas são datadas, ao mesmo tempo que nos perguntamos sobre a viabilidade de pesquisa e formação de profissionais da educação com dados e métodos quantitativos. Acreditamos com Günther (2006) que sim, pelos motivos a seguir.

Hoje em dia, parte daqueles argumentos acadêmicos contra a pesquisa quantitativa em Ciências Humanas estão respondidos ou não fazem mais sentido dado o novo contexto político e tecnológico em que vivemos. Atualmente, ocorre a diversificação das fontes e a ampliação exponencial de sua quantidade e disponibilidade em razão dos fenômenos da internet, da produção e disponibilização eletrônica de uma quantidade massiva de textos e imagens, das redes sociais e das opiniões dadas de forma espontânea e sincera por uma quantidade enorme de pessoas. Diante desse quadro, cada vez mais impõe-se um tratamento tecnológico das evidências, o que é permitido pelo tratamento quantitativo de textos com base em novos softwares. Tais softwares produzem resultados que contribuem para a progressiva diluição das fronteiras entre os métodos quantitativos e qualitativos. Se antes, por exemplo, o método 
qualitativo era caracterizado como uma ciência do texto, hoje, diante da avalanche de textos, a análise quantitativa aparece como um recurso - auxiliar ou principal - que vai se tornando indispensável para lidar com a avalanche de textos oriundos de uma sociedade de massas em que os consumidores de informação, cultura e entretenimento passam também a produtores de conteúdo e de crítica aos conteúdos produzidos.

Um exemplo específico para a comunidade em que nos encontramos é o crescimento exponencial da pesquisa em ensino de História, que cada vez menos se resolve com um tratamento artesanal dos dados. Avançar implica saber, por exemplo, quais são as áreas de reflexão que estão saturadas e quais as carentes, quais dos problemas já estão suficientemente respondidos e quais estão em becos sem saída. Um conjunto imponente de estudos de caso só ultrapassa a sua data e local se sistematizados em processos de síntese que passam pelo tratamento massivo dos dados que produziram. Podem-se destacar aí, por exemplo, o estudo das referências bibliográficas utilizadas pelos pesquisadores e das ligações entre diferentes grupos de pesquisa. Sem esse tipo de visão de conjunto, o risco de uma comunidade de pesquisa cujas conclusões começam a parecer circulares e de pouca utilidade é real.

Entre as razões científicas que depõem a favor da utilização dos métodos quantitativos nas Ciências Humanas, podemos elencar as seguintes, que resumem as considerações de Günther (2006):

a) a adequação dos métodos aos objetos: assim como os métodos qualitativos, os quantitativos também consideram hoje o princípio da abertura, quer dizer, a adequação dos métodos aos objetos e objetivos. Considerar métodos quantitativos nas Ciências Humanas não restringe o campo de visão aos resultados de um questionário fechado, porque há objetos e amostras para os quais o questionário fechado é inferior em qualidade à informação que gerará, mas há outros em que os métodos qualitativos são inadequados ou inviáveis. Na perspectiva de uma integração efetiva, os métodos quantitativos não concorrem com os qualitativos pela exclusividade de objetos, objetivos ou amostras, mas o contrário: abrem a pesquisa para outros objetos, objetivos e amostras, em pesquisas que podem ser complementares e dar o passo seguinte ao que se descobriu pela via qualitativa, e vice-versa. Assim, um tema profundamente pesquisado na perspectiva qualitativa pode ser pesquisado quantitativamente, como é o caso dos tipos de geração de sentido histórico, tema caro à Didática da História (Cerri, 2014). 
b) Assim como nos métodos qualitativos, os quantitativos também permitem uma reflexão contínua na confrontação entre métodos e resultados, ou na interação dinâmica entre o pesquisador e o objeto de estudo. Embora os questionários possam ser fechados, não é fechada a perspectiva de revisão do próprio encaminhamento técnico e metodológico, mas, neste caso, isso se dá principalmente mediante estudos-piloto e testes de hipóteses, que têm uma fundamentação estatística.

c) Os estudos de base quantitativa também são passíveis de generalização argumentativa, quer dizer, a partilha e a submissão ao debate de seus pressupostos metodológicos. Usar um questionário fechado ou uma amostra bem delimitada não implica que os resultados serão certos ou indiscutíveis: debate-se sempre a memória de cálculo, as características da amostra e o histórico da criação de categorias e variáveis.

d) De modo algum os estudos quantitativos significam abandonar o desafio da compreensão da complexidade em favor de uma simplificação do real a variáveis. Todo pesquisador sério tem a clareza de que o objeto de estudo não se limita às suas variáveis, mas entende que a produção de dados de base ampla e a identificação de relações entre eles são uma contribuição fundamental para a compreensão do real em sua complexidade.

e) Por fim, em vários campos das Ciências Humanas e das atividades educacionais, o conhecimento de dados quantitativos e o domínio das condições de sua produção são fundamentais para o debate social e político em defesa, por exemplo, do próprio ensino da História. Basta ver que os costumeiros ataques aos professores, à sua autonomia e às condições de trabalho por iniciativas economicistas e "à prova de professor" (Giroux, 1997) para a educação baseiam sua argumentação em extensos corpos de dados produzidos por entidades como o FMI e o Banco Mundial, contra os quais não temos os nossos próprios dados ou nossa análise crítica dos dados deles para contra-argumentar nessa arena. E a política educacional se decide, em grande parte das vezes, nessa arena. Ao rechaçar os números e desqualificar o quantitativo, é comum que os professores e suas entidades percam por W.O. o confronto com os organismos sustentadores de políticas educacionais que excluem a perspectiva e a experiência dos docentes.

\section{EXPERIÊNCIAS DE DOCENTES \\ DE HistóRIA COM DAdOS QUANTITATIVOS}

O projeto "Jovens e a História no Mercosul” coletou dados por meio de questionários submetidos a 3.913 estudantes e 288 professores do Brasil, 
Argentina, Uruguai, Paraguai e Chile entre 2012 e 2013. ${ }^{2}$ Aos alunos foram feitas, além de questões de perfil pessoal, questões referentes à aprendizagem e atividade em sala de aula, assim como opiniões no campo da cultura histórica e da cultura política. Aos professores, perguntou-se, além de questões do perfil pessoal e profissional, sobre o ensino da História na escola, expectativas e impressões sobre a aprendizagem do aluno e igualmente questões sobre cultura histórica e cultura política. A base de dados produzida contém informações riquíssimas sobre a realidade do ensino e da aprendizagem de História na América do Sul, embora não se trate de uma pesquisa com amostra probabilística, quer dizer, que pretenda representar os universos nacionais, com margens de erro delimitadas: as assertivas que derivam da pesquisa referem-se apenas ao universo da própria amostra. Entretanto, os resultados são igualmente significativos para pensar as condições e o estado atual do ensino e da aprendizagem, assim como elementos da cultura na qual estão imersos professores, alunos e aulas.

Apresentaremos a seguir duas iniciativas que procuraram aproximar os resultados dessa pesquisa quantitativa com a realidade da sala de aula dos professores, em defesa do argumento apresentado no início. Infelizmente, ainda não dispomos de informações para avaliar efetivamente as mudanças nas práticas de sala de aula, assim como nos pressupostos que estão na base da leitura de mundo e da escola por parte dos professores, que são capazes de afetar a docência. Isso também se explica pelo fato de que essas transformações não são mensuráveis facilmente, nem no curto prazo.

O Proyecto Zorzal ${ }^{3}$ (ou Projeto Sabiá, em português, formalmente intitulado "Enseñanza de la historia latinoamericana: recursos, problemas y posibilidades") surgiu por iniciativa e está sob coordenação dos professores María Paula Gonzalez e Ernesto Bohoslavski, da Universidad Nacional de General Sarmiento (UNGS - Argentina). O projeto foi financiado pelo Programa de Apoio ao Setor Educativo do Mercosul (Pasem) e desenvolvido em colaboração com a Universidade Estadual de Ponta Grossa (UEPG) e a Universidade Estadual do Oeste do Paraná (Unioeste).

O Zorzal consistiu em um esforço de processamento, sistematização, análise e difusão dos dados levantados com a pesquisa empírica do projeto "Jovens e a História no Mercosul”, assim como conversão dos resultados dessa 
investigação em material para a formação de professores de história nos países do Mercosul.

Desde o projeto piloto do "Jovens e a História" no final dos anos 2000, apareciam alguns resultados que inspiraram o trabalho do Zorzal: por um lado, que nas aulas na e sobre a América Latina era muito restrito o uso de materiais didáticos não escritos ou textuais, tais como materiais fotográficos, audiovisuais e em multimídia. Além disso, ficava patente a falta de interesse conjugada à pobreza de conhecimentos de história latino-americana entre os jovens pesquisados. A pesquisa principal reencontrou e confirmou esses resultados, e foi sobre essas constatações que se fundou a série de atividades do Zorzal.

O projeto somou os resultados da pesquisa empírica com os resultados de pesquisas acadêmicas desenvolvidas na UNGS e na Unioeste que utilizaram a música e o humor gráfico como fontes para a investigação e compreensão do passado recente nos países do Mercosul, com os documentos levantados ao longo dessas investigações, e com outros que foram identificados, estudados e preparados para atividades de ensino da História do século XX pela equipe do Zorzal.

O principal resultado do trabalho é o site do projeto, apresentado em espanhol, português e guarani (alguns conteúdos). O site funciona como um portal de conteúdo, tanto para os resultados da pesquisa empírica quanto para a seleção de materiais/fontes e propostas didáticas que se relacionam com os resultados: entrevistas com músicos, cartunistas, editores e produtores musicais, reprodução de canções e suas letras, cartazes, charges, tiras e outras peças gráficas publicadas em jornais e revistas do Brasil, Paraguai, Uruguai e Argentina no século XX, materiais de reflexão e propostas para o uso da música e do humor gráfico como fontes para o ensino de História, assim como fontes para a história da cidadania nos países envolvidos, como constituições federais, manifestos de golpes militares e outros.

No site, estão disponíveis também, para uso dos professores, os resultados da pesquisa "Jovens e a História" separados por questões e com comentários explicativos e analíticos gerais. Na mesma direção, há a oferta de dados dinâmicos utilizando os recursos on-line do software Tableau, quais sejam, a possibilidade de trabalhar com grande parte dos resultados das questões do instrumento de coleta de dados do "Jovens e a História", seja no bloco original ou por país, seja desagregando os resultados por algumas variáveis 
disponíveis de perfil dos respondentes, tais como sexo, país, tipo de escola e outros, permitindo algumas análises estatísticas descritivas de forma autônoma e intuitiva.

Figura 1 - Tela do software Tableau em funcionamento no site do Proyecto Zorzal

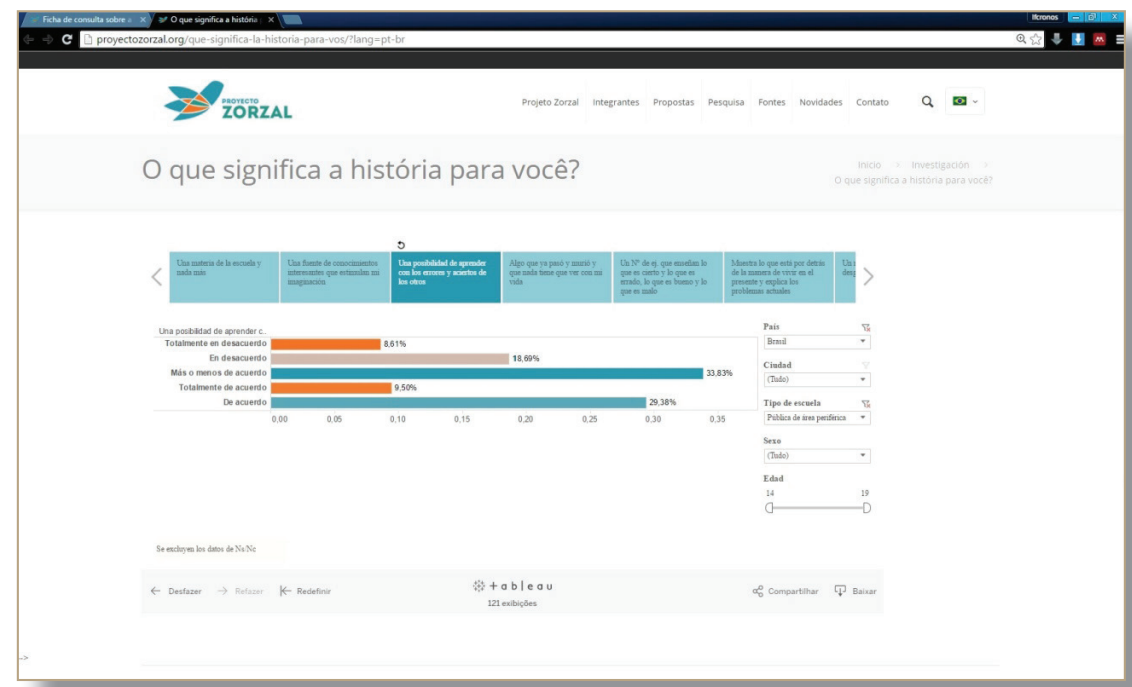

Fonte: disponível em http://proyectozorzal.org; Acesso em: 13 jul. 2016.

Com base nos resultados do "Jovens e a História” em gráficos de síntese por questão, bem como nos relatórios e no acesso aos gráficos pelos recursos do Tableau alocados no site do Zorzal, fizemos a experiência de propor a professores já atuantes bem como a professores em formação o trabalho com dados quantitativos em contextos de formação docente: uma oportunidade ocorreu em noite de trabalho junto a estudantes de professorado (no Brasil, licenciatura) de História da Universidad Nacional Tres de Febrero - Campus Palomar, e outra no contexto da disciplina "Problemas de enseñanza y aprendizaje de Historia" da Maestría en Enseñanza de Historia da mesma universidade, no campus da cidade de Buenos Aires. A experiência com estudantes durou apenas uma noite, mas com os professores mestrandos estendeu-se por quase um mês, entre 2 dias de encontro presencial e um mês de trabalho assíncrono a distância. Guardadas as diferenças, apresentamos a seguir alguns 
resultados iniciais e possibilidades que derivaram dessas experiências, no que apontam para benefícios desse tipo de recurso para a formação e possibilidades para a prática em sala de aula (que não foi acompanhada, mas apareceu como projeção e intenção dos estudantes e professores).

O trabalho com os dados junto a professores, especialmente aquele que se refere à comparação de opiniões e percepções entre os coletivos de estudantes e professores, também enriquece outra perspectiva formativa, que é a sensibilidade para a diferença de pensamento que resulta das distinções culturais entre gerações de um mesmo estrato social, ainda mais profunda quando o professor é de um estrato social e os estudantes são de outro. Incentiva um olhar para o processo de ensino como diálogo com o outro, em que é necessário negociar, em vez de imaginar o processo como transmissão e assimilação de um conhecimento com sentido comum, unívoco, que bastaria transmitir. O trabalho com o dado quantitativo dos alunos soma razões e incentivos para a postura dialógica. Isso pode ter um caráter profilático ou terapêutico diante da predominância, em nossa cultura, da noção de que educação é transmissão de conhecimento para pessoas que são uma versão menor ou mais jovem dos adultos, à espera de ser preenchida por conteúdos providenciados pelos adultos. Não fosse assim, o sucesso de postulados reacionários "contra a doutrinação ideológica nas escolas" no senso comum não se verificaria. Assim, dados sobre os pontos de interesse e de desinteresse dos alunos de determinada faixa etária necessariamente conduzem a uma reflexão sobre as estratégias para pensar e praticar o currículo, como ocorre com o desinteresse dos alunos pela vida cotidiana das pessoas comuns na história, que convive com o alto interesse pela história da própria família, como veremos adiante.

O exercício com os dados do projeto estimulou e favoreceu a reflexão sobre métodos utilizados no ensino e como eles são percebidos pelos estudantes: a frequência com a qual os professores afirmam utilizar aulas expositivas e livros didáticos corresponde exatamente à frequência percebida pelos estudantes, ou seja, como práticas centrais da aula de História. Entretanto, métodos e práticas alternativas como teatro, trabalhos em grupo e visitas a museus são relatados diferentemente por estudantes e professores. O mesmo se dá com os objetivos das aulas declarados por professores e percebidos por estudantes; a reflexão sobre as diferenças é um exercício de retroalimentação para os 
docentes sobre a sua prática, a partir da informação sobre como o interlocutor lê e avalia a ação docente.

Os dados dos gráficos a seguir têm suas grandezas expressas na média de uma escala que vai de -2 a 2 , sendo que -2 é a atitude mais negativa em relação à afirmação ou assunto dado (nenhum interesse, discordo totalmente etc.), zero é a medida da neutralidade ou indiferença, e 2 é a tradução da resposta mais positiva (interesse total, concordo totalmente etc.). Assim, um resultado 0,5 significa que a média das respostas ficou entre a indiferença e a concordância simples, e um resultado -1,5 significa que a média das respostas ficou entre a discordância simples e a discordância total. Ressalvando os limites da média como medida de tendência central (a sensibilidade a resultados extremos e a possibilidade de distribuições diferentes de respostas produzirem médias muito parecidas), deve-se destacar que a média serve como síntese, neste caso como visão geral da tendência de um grupo, uma vez que reduz milhares de números a apenas um. Além disso, uma amostra que tenha um número expressivo de respostas tende a diminuir o efeito de resultados extremos e obter uma distribuição normal das respostas, quer dizer, uma situação em que os resultados se distribuem com a maioria das respostas próximas à média e as respostas mais distantes da média vão figurando em número progressivamente menor.

Há que se considerar que tanto os professores em formação quanto aqueles que já estão em atividade são portadores de impressões e avaliações prévias sobre os temas das questões da pesquisa que desenvolvemos. Essas ideias tácitas derivam da experiência, tanto a de professor quanto a de aluno. Entretanto, ao contrário do que se possa pensar, os resultados da pesquisa quantitativa sobre esse tipo de questão não necessariamente confirmam as impressões e avaliações subjetivas. Mesmo quando confirmam, ainda assim não são resultados irrelevantes, porque adicionam dados até então inexistentes sobre a dimensão ou proporção de concordâncias, discordâncias, preferências ou crenças e o sentido (proporcionalmente direto ou inverso) da relação entre fatores diferentes. O gráfico sobre o interesse quanto a períodos da história está entre um e outro caso: embora os participantes do exercício de análise pudessem intuir parte dos resultados, foram surpreendidos pela força do interesse em história recente e na história primitiva, e pelo interesse relativamente menor 
Gráfico 1 - Comparação entre as médias de interesse de estudantes por períodos da história por país

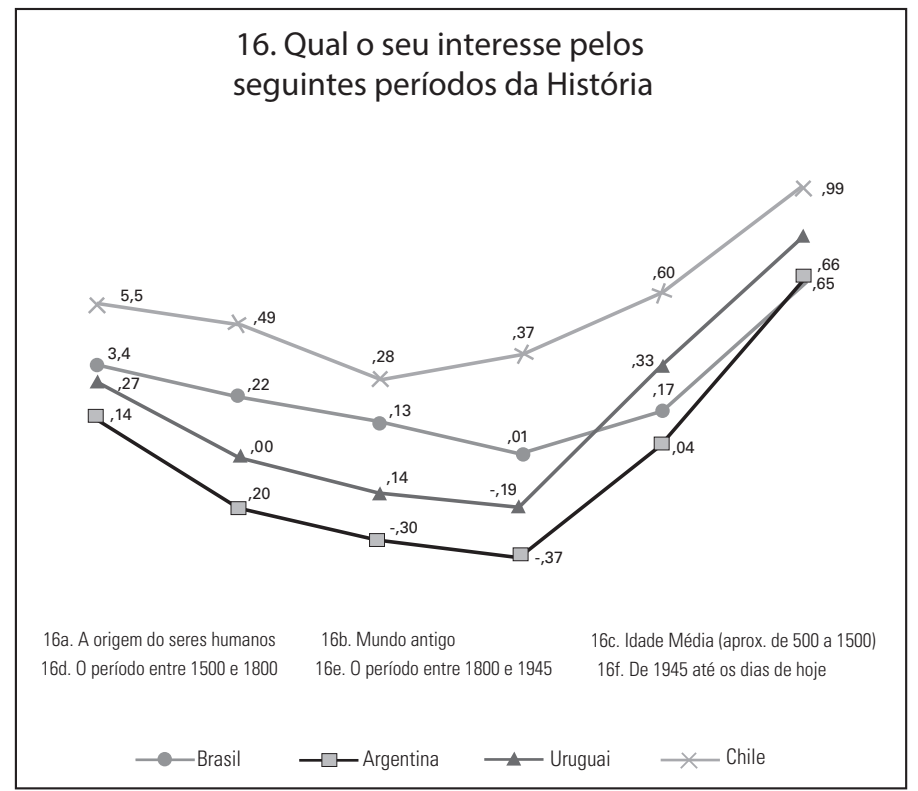

Fonte: Dados do projeto "Jovens e a História no Mercosul" organizados pelo autor, 2013.

quanto aos outros períodos, fenômeno comum em todos os países em que foram coletados dados para a pesquisa.

O debate decorrente da projeção e interpretação desse gráfico deixou claro que os aprendizes e docentes de História naturalmente não se submetem à ideia de que os resultados quantitativos são verdades absolutas. Pelo contrário, rapidamente foram feitas perguntas pedindo maior detalhamento sobre a amostra e os procedimentos de coleta, e as falas analisaram criticamente a formatação da pergunta e das respostas, imaginando as possibilidades de decodificação desviante por parte dos respondentes. Enfim, os participantes desse exercício submeteram espontaneamente os resultados a uma série de relativizações e limites das condições de validade da informação. Nesse sentido, o relativo estranhamento quanto à metodologia da pesquisa e à forma de apresentação dos dados significou um estímulo para a vigilância epistemológica quanto à pesquisa, em vez de uma aceitação acrítica dos dados, o que indicou 
uma animadora disposição de análise crítica, que é um valor construído pela formação inicial e continuada e, certamente, pelos embates políticos e sindicais nos quais os docentes precisam lidar criticamente com dados e informações, na disputa pelas narrativas que legitimem as reivindicações docentes e críticas às políticas governamentais para a educação.

Junto ou na sequência desse escrutínio sobre a validade dos resultados, os participantes procuraram imediatamente elaborar hipóteses que explicassem os resultados apresentados, algumas das quais podem ser testadas cotejando esses dados com os de respostas a outras questões, ou ainda desagregando os dados por diversas variáveis. Nesse tópico, a disposição dos dados on-line e a possibilidade de manipulá-los com as ferramentas do software Tableau, no site do projeto Zorzal, foram de imensa valia.

Quando consultados, os participantes puseram-se a identificar e projetar consequências que essas informações e esse tipo de informações trazem para o ensino. Primeiramente, foi possível identificar que tanto o surgimento da humanidade e seus passos primitivos quanto os anos mais recentes da história coincidem em ser os temas/períodos de maior interesse dos alunos e de menor dedicação por parte dos currículos, programas e desenvolvimento efetivo em sala de aula. Ainda que o currículo não tenha que se pautar, obviamente, apenas pelos interesses dos alunos, esse fator é importantíssimo no momento de traçar estratégias para mobilizar a atenção e motivar os discentes. Nas discussões, ainda, a adesão a essa metodologia de abordagem do ensino e da aprendizagem ficou patente quando os professores apresentaram uma demanda no sentido de que esse tipo de pesquisa fosse feito de forma específica para as suas turmas em seus locais de trabalho, de modo a orientar o planejamento de atividades didáticas. É inegável que um curso que atenda mais acuradamente às características de cada escola ou grupo de alunos é uma vantagem capaz de promover um avanço indiscutível na qualidade do ensino e da aprendizagem. Com isso, a aplicação de questões fechadas deixa de ter o caráter limitado de uma avaliação padronizada da aprendizagem (que todavia não deve ser desprezada, por ser caminho para o acesso ao ensino superior e oportunidades de trabalho de maior qualidade) para incorporar a dimensão de conhecer mais amplamente o aluno e projetar aprendizagem de forma cada vez mais customizada. Os próprios resultados podem vir a ser apresentados e discutidos com os alunos, com o que se ganha em termos de uma 
autoconsciência mais precisa de características pessoais e coletivas por parte do corpo discente, permitindo a reflexão sobre a própria trajetória de formação: por que sou semelhante a meus colegas ou diferente deles em algumas coisas e noutras não? Por fim, essas demandas indicam, para as licenciaturas ou professorados, a incorporação de tecnologias que abram espaço para leituras e diagnósticos das escolas e das classes que complementem a observação com outra família de métodos de desvendamento das características do corpo discente, que podem ser imediatamente compartilhadas com o supervisor do estágio para incorporação rápida ao planejamento e às atividades de ensino, fortalecendo a via de mão dupla de colaboração e sinergia entre a escola básica e a escola de formação de professores.

No que tange ao aspecto formativo do docente, os dados do Gráfico 2 aportam uma contribuição/reforço à necessária consciência das diferenças constantes entre o pensamento do adulto/professor e o do jovem/estudante, assim como convocam uma consequência operacional, na sala de aula, para essa consciência renovada ou reforçada. Nós, professores, já sabemos, mas tendemos a nos esquecer - ou não dar consequências práticas à lembrança, o que dá no mesmo - das diferenças estruturais de nosso pensamento com o pensamento de nossos estudantes. Isso não resulta apenas de uma diferença geracional, que aporta o tempo de vida e experiência como um fator de diferenciação, mas também e principalmente de uma diferença de formação profissional. Juntamente à clareza de que os estudantes não são folhas de branco (ou, dizendo de modo mais atualizado, cartões de memória formatados), essa consciência promove uma autovigilância sobre a contínua necessidade de nos traduzirmos e mantermos em primeiro plano a consideração das estruturas diferentes de produção de interesses e sentidos por parte dos jovens.

No nível do trabalho com as perspectivas metodológicas e leituras do processo de ensino e aprendizagem por parte do professor, os dados quantitativos permitiram aos participantes confirmar, rejeitar ou relativizar as ideias tácitas que os professores formam sobre os alunos e suas preferências, opiniões e conhecimentos. Mais que isso, faz refletir sobre a importância e a utilidade pedagógica de conhecer com precisão crescente o conhecimento dos alunos, e estabelece a demanda de que o ideal seria que o tipo de levantamento que foi feito pelo projeto "Jovens e a História" fosse realizado exatamente com o conjunto de alunos com os quais cada um trabalha. Esse aporte tecnológico na 
Gráfico 2 - Comparação de médias de interesse por temas entre alunos e a estimativa dos professores

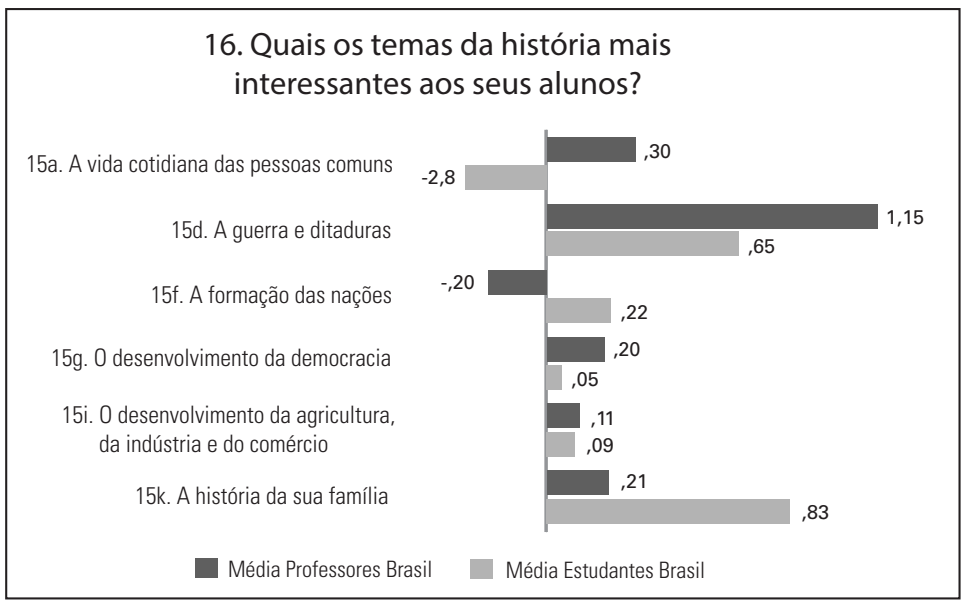

Fonte: Dados do projeto "Jovens e a História no Mercosul" organizados pelo autor, 2013.

assessoria ao docente estreitaria a relação de conhecimento entre professores e alunos, ampliando a precisão do planejamento de ensino e aprendizagem e provavelmente a sua eficiência.

Alguns resultados já eram esperados - embora reconhecendo o desconhecimento da dimensão exata do resultado - em razão da experiência docente, seja profissional, seja dos estágios: por exemplo, o interesse por ditaduras e guerras, especialmente o interesse pela Segunda Guerra Mundial. Entretanto, uma surpresa é a dicotomia apresentada pelos resultados da primeira e da última pergunta: ao mesmo tempo que os estudantes revelam menos interesse pela vida cotidiana das pessoas comuns do que os professores da pesquisa - e da atividade de formação - avaliaram, revelam um interesse muito mais amplo do que o esperado pela história de suas próprias famílias.

A dinâmica analítica dos grupos com os quais trabalhamos rapidamente construiu hipóteses para explicar essa relação, no mesmo ímpeto com o qual se elaborou coletivamente uma sugestão para usar esses dados a favor do ensino: para a história recente, e em muitos casos a história nacional desde os fins do século XIX, é possível incorporar a família do aluno como personagem e como testemunha de vários processos que geralmente são ensinados de uma 
forma impessoal: a imigração, a integração de negros e índios e seus descendentes na sociedade dominada pelos brancos, os processos de industrialização, de êxodo rural e de urbanização, enfim, tantos temas que podem ser abordados a partir de uma fórmula que naturalmente torna os conteúdos mais significativos, ao mesmo tempo que os adapta à especificidade e identidade das classes escolares e dos indivíduos estudantes, e ainda pode ter o condão de aproximar a família da escola. Por sua vez, a pequena expectativa em torno do conhecimento sobre a democracia demanda atenção dos sujeitos da escola, assim como o interesse por conflitos (guerras e ditaduras) parece corroborar o dado do Gráfico 1, que demonstra o interesse dos estudantes pela história recente, que tem relativamente pouco espaço no currículo efetivamente desenvolvido nas escolas brasileiras.

\section{CONSIDERAÇÕES FINAIS}

Pretendemos com este ensaio haver contribuído para a efetiva superação de renitentes polarizações entre as metodologias quantitativas e as qualitativas, que se verificam em várias estratégias discursivas, inclusive de negação de que a dicotomia exista ou de desqualificação das especificidades dos métodos quantitativos.

Procuramos demonstrar, ainda que de modo preliminar e provisório, a possibilidade da contribuição de pesquisas e dados quantitativos na formação docente e na reflexão didática de professores, interferindo positivamente em suas concepções e práticas em sala de aula.

Aponta-se, como desenvolvimento possível, que a produção de questionários customizados de acordo com as necessidades dos professores (ou seja, aplicados diretamente às suas turmas, adaptados com perguntas de seu interesse), bem como a aplicação e disponibilização de dados para eles (com análise e cruzamentos a partir de questões e hipóteses postas pelos docentes), constituem uma perspectiva duplamente importante: em primeiro lugar, para dar continuidade e aprofundamento à contribuição desse tipo de estudo para a prática docente e, em segundo lugar, para criar meios de investigar empiricamente essa contribuição. 


\section{REFERÊNCIAS}

AGRESTI, Alan; FINLAY, Barbara. Métodos estatísticos para as ciências sociais. Trad. Lori Viali. 4.ed. Porto Alegre: Penso, 2012.

ANGVIK, M.; BORRIES, B. Youth and History: A comparative European survey on historical consciousness and political attitudes among adolescents. Hamburg: Körber-Stiftung; Heinrich-Heine-Buchh, 1997.

BARROS, José D’A. A história serial e história quantitativa no movimento dos Annales. História Revista, Goiânia, v.17, n.1, p.203-222, 2012. Disponível em: http:// dx.doi.org/10.5216/hr.v17i1.21693; Acesso em: 29 maio 2016.

BORGES, Jorge Luís. Sobre o rigor na ciência. In: . História universal da infâmia. Trad. José Bento. Lisboa: Assírio \& Alvim, 1982.

CERRI, Luis F. Tipos de geração de sentido histórico - um ensaio com dados quantitativos. In: SCHMIDT, Maria A.; BARCA, Isabel; URBAN, Ana C. (Org.) Passados possíveis: a educação histórica em debate. Ijuí: Ed. Unijuí, 2014. v.1, p.179-194.

CHIZZOTTI, Antonio. A pesquisa qualitativa em ciências humanas e sociais: evolução e desafios. Revista Portuguesa de Educação, v.16, n.2, p.221-236, 2003.

GIROUX, Henry A. Os professores como intelectuais. Porto Alegre: Artmed, 1997.

GÜNTHER, Hartmut. Pesquisa qualitativa versus pesquisa quantitativa: esta é a questão? Psicologia: Teoria e Pesquisa, Brasília, v.22, n.2, p.201-210, maio/ago. 2006.

LAVILLE, Christian; DIONE, Jean. A construção do saber: manual da metodologia da pesquisa em ciências humanas. Trad. Heloísa Monteiro e Francisco Settineri. Porto Alegre: Artmed; Belo Horizonte: Ed. UFMG, 2007.

MINAYO, Maria C. S.; SANCHES, Odécio. Quantitativo-Qualitativo: oposição ou complementaridade? Cadernos de Saúde Pública, Rio de Janeiro, v.9, n.3, p.239262, jul./set. 1993.

RAMOS, Madalena; CARVALHO, Helena. Os métodos quantitativos no Ensino Superior: uma tipologia de representações. Educação e Pesquisa, São Paulo, v.35, n.1, p. 15-32, jan./abr. 2009.

RAMOS, Marília P. Métodos quantitativos e a pesquisa em Ciências Sociais. Lógica e utilidade do uso da quantificação nas explicações dos fenômenos sociais. Mediações, Londrina, v.18 n.1, p.55-65, jan./jun. 2013.

SCHMIDT, Maria A. M. S.; GARCIA, Tânia M. B. Pesquisas em Educação Histórica: algumas experiências. Educar, Curitiba, n. especial, p.11-31, 2006.

THOMPSON, Edward P. A miséria da teoria. Ou um planetário de erros. Rio de Janeiro: Zahar, 1981. 
Luis Fernando Cerri

\section{NOTAS}

${ }^{1}$ Os projetos mencionados neste texto receberam apoio financeiro, respectivamente: Projeto Jovens e a História: CNPq e Fundação Araucária; Proyecto Zorzal: Programa de Apoyo al Sector Educativo Del Mercosur (Pasem)/ União Europeia.

${ }^{2}$ Ver mais informações em http://gedhiblog.blogspot.com.br.

${ }^{3}$ Ver mais informações em http://www.proyectozorzal.org.

Artigo recebido em 13 de julho de 2016. Aprovado em 13 de setembro de 2016. 